\title{
Baseline Sensitivity and Action Mechanism of Propamidine Against Alternaria brassicicola, the Causal Agent of Dark Leaf Spot on Cabbage
}

\author{
Yong Wang, Miaomiao Wang, Mingxia Zhou, Xing Zhang, and Juntao Feng ${ }^{\dagger}$ \\ Research and Development Center of Biorational Pesticides, Northwest A \& F University, Yangling 712100, Shaanxi, China
}

\begin{abstract}
In the current study, a total of 53 isolates of Alternaria brassicicola collected from Shaanxi Province of China were characterized for their sensitivity to propamidine. The $\mathrm{EC}_{50}(50 \%$ effective concentration) values for propamidine inhibiting mycelial growth and spore germination ranged from 0.515 to $3.247 \mu \mathrm{g} / \mathrm{ml}$ and 0.393 to $2.982 \mu \mathrm{g} / \mathrm{ml}$, with average $\mathrm{EC}_{50}$ values of $1.327 \pm 0.198 \mu \mathrm{g} / \mathrm{ml}$ and $1.106 \pm 0.113 \mu \mathrm{g} / \mathrm{ml}$, respectively. In greenhouse experiments, propamidine at $100 \mu \mathrm{g} / \mathrm{ml}$ provided $>90 \%$ efficacy against dark leaf spot on cabbage, which was higher than the efficacy obtained by azoxystrobin at the same concentra-

Interestingly, colony color faded after treatment with propamidine compared with that of the untreated parental isolates. Importantly, the expressions of melanin biosynthesis-associated genes Amrl, Scdl, Brnl, and $B r n 2$ were downregulated at different levels. The obtained baseline sensitivity and control efficacy data suggested that propamidine inhibited not only growth of $A$. brassicicola but also melanin biosynthesis, which could reduce the biocompatibility of $A$. brassicicola in the field. These biological characteristics encourage further investigation of the mechanism of action of propamidine against $A$. brassicicola.
\end{abstract} tion. After treatment with propamidine, fungal growth distortions were observed in the form of excess mycelial branching, thickened cell walls, decreased cell membrane permeability, and increased chitin content.
Keywords: propamidine, Alternaria brassicicola, baseline sensitivity, action mechanism
Cabbage (Brassica oleracea var capitata $\mathrm{L}$.) is one of the most popular and widely grown vegetables worldwide, especially in China, and it accounts for $40 \%$ of global production (Ayaz et al. 2006; Zhang et al. 2007). Dark leaf spot, a disease caused by the filamentous ascomycete Alternaria brassicicola (Schwein). Wiltshire, is one of the most devastating diseases of cabbage (Cho et al. 2012). All developmental phases of cabbage may be infected by A. brassicicola, from seedling to maturity (Kim et al. 2007). This disease occurs throughout major cabbagegrowing regions worldwide, including China, Japan, Canada, India, and the United States. Yield losses up to $70 \%$ caused by the disease have been reported (Kreis et al. 2016; Chen et al. 2017; Nowakowska et al. 2019; Srivastava et al. 2012). Conidia produced by A. brassicicola are dispersed by wind and rain splash, and the disease is difficult to manage (Manhas and Kaur 2016).

The use of resistant cultivars would be an ideal method to control the disease, but crucifer cultivars resistant to dark leaf spot are currently unavailable (Pedras et al. 2009). Consequently, chemical control is still the most reliable and cost-effective way of reducing disease incidence. Fungicides with differing modes of action commonly used in the management of dark leaf spot include benzimidazoles (carbendazim), dicarboximides (iprodione), phenylpyrroles (fludioxonil), strobilurins (azoxystrobin), and dithiocarbamates (mancozeb) (Iacomi-Vasilescu et al. 2004; Manhas and Kaur 2016). To date, there have been no reported control failures for fungicides used to manage $A$. brassicicola; however, resistance to these fungicide groups has been widely reported in many other plant pathogens. For example, resistance to carbendazim has been reported for Sclerotinia sclerotiorum, Botrytis cinerea, and Fusarium

${ }^{\dagger}$ Corresponding author: J. Feng; jtfeng@126.com

Funding: This study was sponsored by the National Natural Science Foundation of China (grant 31801762).

*The $\boldsymbol{e}$-Xtra logo stands for "electronic extra" and indicates that one supplementary figure and one supplementary table are published online.

The author(s) declare no conflict of interest.

Accepted for publication 12 July 2019.

(C) 2020 The American Phytopathological Society graminearum (Beever et al. 1989; Chen and Zhou 2009; Xu et al. 2015); resistance to iprodione and fludioxonil has been reported for A. brassicicola (Iacomi-Vasilescu et al. 2004); resistance to azoxystrobin has been reported for $>30$ pathogen species, such as Alternaria alternata, B. cinerea, and Plasmopara viticola (Bartlett et al. 2002; Köller 2002); and resistance to mancozeb has been detected for Fulvia fulva, Colletotrichum gloeosporioides, and A. alternata (Gullino et al. 2010; Malandrakis et al. 2015; Wang et al. 2005; Yang et al. 2013). Considering the potential fungicide resistance risk with $A$. brassicicola, it is necessary to screen new alternative fungicides for disease management.

Propamidine belongs to a novel chemical class of aromatic diamidine compounds, which include other compounds such as betamidine, butamidine, and pentamidine (Hou et al. 2010). The antifungal activity of propamidine against agricultural fungi was first documented against B. cinerea, a causal agent of gray mold. Subsequent research found that propamidine also exhibited high efficacy against other fungal diseases, including Sclerotinia stem rot caused by S. sclerotiorum and apple valsa canker caused by Valsa mali Miyabe \& Yamada (Wang et al. 2017, 2018). However, the mechanism of action of propamidine is still unclear. In China, propamidine has been registered since 2004, and only for the control of gray mold on vegetables.

There is little information about the sensitivity and resistance risk of A. brassicicola to propamidine. Such a study would provide an opportunity to study the antifungal activity and mechanism of action of propamidine against $A$. brassicicola prior to it being registered for use to manage dark leaf spot on cabbage in China.

The aims of the present study were to: (i) establish the baseline sensitivity of $A$. brassicicola to propamidine using inhibition of mycelial growth and spore germination data; (ii) evaluate the efficacy of propamidine against dark leaf spot on cabbage in greenhouse experiments; (iii) investigate the effect of propamidine on the morphology of $A$. brassicicola; and (iv) explore the mechanism of action of propamidine against $A$. brassicicola.

\section{Materials and Methods}

Isolates, media, and fungicides. A total of 53 A. brassicicola isolates were collected from naturally infected cabbages in Shaanxi Province during 2017 and 2018. All isolates had been exposed to carbendazim, a benzimidazole fungicide. Isolates were confirmed by microscopic observations of morphological characteristics and purified by three rounds of single-spore isolation. 
Potato dextrose agar (PDA; $200 \mathrm{~g}$ of potato, $16 \mathrm{~g}$ of agar, and $20 \mathrm{~g}$ of dextrose per liter of distilled water) was used for the mycelial sensitivity test, and water agar (WA; $20 \mathrm{~g}$ of agar power per liter of distilled water) was used in the spore germination test.

Technical grade propamidine $(97.0 \%)$ provided by the Research and Development Center of Biorational Pesticide of Northwest A \& F University and azoxystrobin (97.8\%; Syngenta China Co., Ltd., China) were dissolved in methanol at $10 \mathrm{mg} / \mathrm{ml}$ as stock solutions.

Baseline sensitivity of $\boldsymbol{A}$. brassicicola to propamidine. Mycelial plugs (diameter, $5 \mathrm{~mm}$ ) taken from the edge of a 6-day-old colony of each A. brassicicola isolate were transferred to a series of PDA plates containing $0,0.625,1.25,2.5,5$, or $10 \mu \mathrm{g} / \mathrm{ml}$ of propamidine. After incubation at $25^{\circ} \mathrm{C}$ in darkness for 6 days, colony diameters were measured at right angles, and the effective concentration at which the mycelial growth rate was inhibited by $50 \%\left(\mathrm{EC}_{50}\right)$ was calculated according to probit analysis (Ma et al. 2009). The experiment was performed twice with three replicates per concentration.

The effects of propamidine on spore germination of A. brassicicola isolates were measured according to the method described in previous studies with minor modifications (Manhas and Kaur 2016; Mc 2010; Zhang et al. 2014). Spore suspensions $\left(1 \times 10^{5} \mathrm{ml}^{-1}\right)$ for each isolate were prepared in sterile distilled water from 6-day-old colonies. The suspensions were then transferred to WA plates containing $0,0.625$, $1.25,2.5,5$, or $10 \mu \mathrm{g} / \mathrm{ml}$ of propamidine. After incubation at $25^{\circ} \mathrm{C}$ in darkness for $24 \mathrm{~h}$, the percentage of spore germination (200 spores for each treatment) was observed under a microscope using a micrometre. A spore was scored as germinated when the germ tube length was at least half the conidium length, and the $\mathrm{EC}_{50}$ was calculated. The experiment was performed twice with three replicates per treatment.

Efficacy of propamidine against $\boldsymbol{A}$. brassicicola. The efficacy of propamidine against $A$. brassicicola was assayed in pot experiments. Cabbage plants (Zhong gan 11) with four to six leaves were sprayed until run-off with propamidine at concentrations of 25,50 , or $100 \mu \mathrm{g} /$ $\mathrm{ml}$ and azoxystrobin (reference fungicide) at $100 \mu \mathrm{g} / \mathrm{ml}$. Plants sprayed with water were used as a control. Plants were left to dry naturally; then, leaves were wounded with a sterilized needle (diameter, $0.5 \mathrm{~mm}$ ) and inoculated with mycelia plugs (one plug per leaf and three leaves per plant) cut from the margin of 6-day-old colonies of the A. brassicicola isolates YL12 and RG5 (randomly selected). All plants were placed in a growth chamber at 20 to $25^{\circ} \mathrm{C}$ with a 12-h photoperiod and $80 \% \mathrm{RH}$. After 6 days, the diameter of each lesion was measured and the control efficacy (the reduced severity relative to the control) was calculated as follows:

$$
\begin{aligned}
\text { Control efficacy }= & {[\text { (lesion diameter of control }} \\
& - \text { lesion diameter of treatment }) / \\
& (\text { lesion diameter of control }-0.5)] \times 100
\end{aligned}
$$

The experiments were performed twice with six plants per fungicide treatment.

Effect of propamidine on mycelial and colony morphology. Mycelial plugs (diameter, $5 \mathrm{~mm}$ ) cut from the leading edge of actively growing colonies of isolates YL12 and RG5 were transferred to PDA plates amended with propamidine at their respective $\mathrm{EC}_{50}$ values. PDA plates without propamidine were used as the control. After $72 \mathrm{~h}$ of culture at $25^{\circ} \mathrm{C}$ in a growth chamber, the margin of the colony $(10 \mathrm{~mm} \times$ $10 \mathrm{~mm}$ ) was transferred to slide glass. The morphology of the mycelial surface was observed with a scanning electron microscope (SEM; JSM-6360LV, Japan) and transmission electron microscope (TEM; HITACHI Transmission Electron Microscope HT7700, Japan) (Wang et al. 2017).

To test the effect of propamidine on colony morphology, mycelial plugs were transferred to PDA plates treated with propamidine at their $\mathrm{EC}_{10}$ and $\mathrm{EC}_{20}$ values. After incubation at $25^{\circ} \mathrm{C}$ in darkness for 1 week, the colonies were photographed. The experiments were performed twice with three replicates per treatment.

Effect of propamidine on cell membrane permeability. Two $A$. brassicicola isolates, YL12 and RG5, were used in this experiment. Ten mycelial plugs taken from the edge of a 6-day-old colony were transferred to $250-\mathrm{ml}$ flasks containing $100 \mathrm{ml}$ of potato dextrose broth
(PDB; PDA without agar). After incubation on a shaker set at $175 \mathrm{rpm}, 25^{\circ} \mathrm{C}$, and in darkness for 4 days, three flasks of each treatment were supplemented with propamidine at their respective $\mathrm{EC}_{50}$ values. After shaking for an additional $24 \mathrm{~h}$, mycelia were collected, strained through three layers of filter paper, and washed with distilled water three times. Then, $0.2 \mathrm{~g}$ of mycelia per sample was suspended in $20 \mathrm{ml}$ of distilled water, and the electrical conductivity of the distilled water was measured after $0.5,1,2,3,4$, and $5 \mathrm{~h}$ with an electrical conductivity meter (S320 Sevencompact; Mettler Toledo, Switzerland). After $5 \mathrm{~h}$, each sample was boiled for $5 \mathrm{~min}$, and the final conductivity was determined. The relative conductivity was calculated as follows (Zhang et al. 2018):

relative conductivity $=$ conductivity $/$ final conductivity $\times 100$

The experiment was conducted three times with three flasks per treatment.

Effect of propamidine on chitin content. Two isolates, YL12 and RG5, were used for the chitin ( $N$-acetylglucosamine, GlcNAc) content test using the Morgan-Elson method according to previous studies, with some modifications (Costa-de-Oliveira et al. 2013; Fortwendel et al. 2009; Walker et al. 2008). Briefly, 5-mm mycelial plugs cultured in flasks of PDB were treated with propamidine at their respective $\mathrm{EC}_{50}$ values and collected as described. For each treatment, $5 \mathrm{mg}$ of dry mycelia was suspended in $1 \mathrm{ml}$ of $6 \% \mathrm{KOH}$ and heated at $80^{\circ} \mathrm{C}$ for $90 \mathrm{~min}$. Samples were centrifuged at $12,000 \mathrm{rpm}$ for $10 \mathrm{~min}$, and the supernatant was discarded. The precipitates were resuspended in $1 \mathrm{ml}$ of PBS in three cycles of centrifugation and resuspension $(12,000 \mathrm{rpm}, 10 \mathrm{~min})$. The precipitates were finally resuspended in $0.5 \mathrm{ml}$ of McIlvaine's buffer ( $\mathrm{pH} 6.0$ ), and $100 \mu \mathrm{l}(5 \mathrm{mg} / \mathrm{ml}$ in phosphate-buffered saline) of Streptomyces plicatus chitinase (Sigma, USA) was added to hydrolyze chitin to GlcNAc. After the samples were incubated at $37^{\circ} \mathrm{C}$ for $24 \mathrm{~h}$ with gentle mixing, $100 \mu \mathrm{l}$ of each sample was combined with $100 \mu \mathrm{l}$ of $0.27 \mathrm{M}$ Mosadium borate $(\mathrm{pH} 9.0)$ in a 1.5-ml centrifuge tube and heated at $100^{\circ} \mathrm{C}$ for $10 \mathrm{~min}$. Then, $1 \mathrm{ml}$ of freshly diluted (1:10) Ehrlich's reagent ( $10 \mathrm{~g} p$-dimethylaminobenzaldehyde in $12.5 \mathrm{ml}$ of concentrated $\mathrm{HCl}$ and $87.5 \mathrm{ml}$ glacial acetic acid) was added. After incubating at $37^{\circ} \mathrm{C}$ for $20 \mathrm{~min}$, the absorbance of the sample at $585 \mathrm{~nm}$ was recorded. Standard curves were established from stocks of 0.2 to $2.0 \mathrm{mM}$ GlcNAc (Sigma, USA) (Zhang et al. 2010). The experiment was repeated three times with three flasks per treatment.

Effect of propamidine on the expression of genes associated with melanin biosynthesis. Previous studies have demonstrated that the Alternaria melanin regulation gene Amrl (GenBank accession number in NCBI: JF487829), scytalone dehydratase gene Scd1 (Ab03393.1), 1,3,8-trihydroxynaphthalene (T3HN) gene Brnl (Ab02276.1), and 1,3,6,8-tetrahydroxynaphthalene (T4HN) gene Brn2 (Ab022751) were involved in melanin biosynthesis (Cho et al. 2012; Tsuji et al. 2002). Therefore, real-time quantitative reversetranscription PCR (qRT-PCR) was used to test the expression levels of these genes in response to propamidine exposure. Two A. brassicicola isolates, YL12 and RG5, were used in this test, and the experiment was conducted as follows: 10 mycelial plugs cut from the margin of each 6-day-old colony were transferred to 250 -ml flasks containing $100 \mathrm{ml}$ of PDB. After shake incubation at $175 \mathrm{rpm}$ and $25^{\circ} \mathrm{C}$ for 4 days, some flasks were supplemented with propamidine at their respective $\mathrm{EC}_{50}$ values. After shaking for an additional $24 \mathrm{~h}$, mycelia were collected. Total RNA was extracted using the TRIzol Reagent (Invitrogen). The extracted RNA was treated with DNase and used for cDNA synthesis with a PrimeScript RT reagent kit (TaKaRa). The qRT-PCR amplifications were performed using a CFX96 real-time detection system (Bio-Rad, Hercules, CA) using SYBR Premix Ex Taq II (Takara, Dalian). Using the genome sequence of $A$. brassicicola (https:// jgi.doe.gov/Abrassicicola), the primers listed in Table 1 were designed according to a previous study (Cho et al. 2012). Relative expression levels of each gene were calculated using the $2^{-\Delta \Delta \mathrm{Ct}}$ method (Livak and Schmittgen 2001). Each treatment had three technical replicates, and the experiment was conducted with three biological replicates.

Data analysis. All data obtained were analyzed using an analysis of variance (ANOVA) with SPSS 22.0 (SPSS Inc., Chicago, IL). A significant difference analysis of the data of $\mathrm{EC}_{50}$ values was 
performed and the biological characteristics were determined using Fisher's least significant difference (LSD) test at 0.05 levels.

\section{Results}

Baseline sensitivity of $\boldsymbol{A}$. brassicicola to propamidine. None of the 53 A. brassicicola isolates used in this study had been exposed to propamidine. The $\mathrm{EC}_{50}$ values of each isolate were calculated by regressing the percentage growth inhibition against the log-transformed fungicide concentration (Ma et al. 2009). The mycelial growth inhibition assays indicated that the $\mathrm{EC}_{50}$ values for propamidine ranged from 0.515 to $3.247 \mu \mathrm{g} / \mathrm{ml}$, with a mean of $1.327 \mu \mathrm{g} / \mathrm{ml} \pm$ $0.198 \mu \mathrm{g} / \mathrm{ml}$. The spore germination inhibition assays indicated that the $\mathrm{EC}_{50}$ values ranged from 0.393 to $2.982 \mu \mathrm{g} / \mathrm{ml}$, with a mean of $1.106 \pm 0.113 \mu \mathrm{g} / \mathrm{ml}$. The frequency distribution of the $\mathrm{EC}_{50}$ values for both mycelial growth and spore germination were unimodal with a narrow range (Fig. 1), and the variation factor values (VF; the maximum $\mathrm{EC}_{50}$ value/the minimum $\mathrm{EC}_{50}$ value) were 6.30 and 7.59, respectively.

Efficacy of propamidine against $\boldsymbol{A}$. brassicicola. On cabbage leaves, large lesions developed on control plants exposed to $A$. brassicicola isolates YL12 and RG5 when sprayed with only water. The control efficacy of propamidine against $A$. brassicicola on potted cabbage plants at $100 \mu \mathrm{g} / \mathrm{ml}$ provided $90.7 \%$ efficacy, which was better compared to the efficacy obtained by the reference fungicide azoxystrobin at the same concentration. When propamidine was sprayed at $50 \mu \mathrm{g} / \mathrm{ml}, 65.3 \%$ control efficacy was observed. Moreover, nearly

Table 2. Efficacy of propamidine against A. brassicicola in pot experiments ${ }^{y}$

\begin{tabular}{lll}
\hline Treatment & Lesion diameter $(\mathrm{cm})$ & Control efficacy $(\%)^{\mathrm{z}}$
\end{tabular}

Propamidine $(25 \mu \mathrm{g} / \mathrm{ml})$

Propamidine $(50 \mu \mathrm{g} / \mathrm{ml})$

Propamidine $(100 \mu \mathrm{g} / \mathrm{ml})$

$2.37 \mathrm{~b}$

$39.87 \mathrm{c}$

$1.58 \mathrm{c} \quad 65.27 \mathrm{~b}$

Azoxystrobin $(100 \mu \mathrm{g} / \mathrm{ml})$

$0.79 \mathrm{~d}$

90.68 a

Water

$0.92 \mathrm{~d}$

86.50 a

y Data are the means of two isolates, YL12 and RG5. Mean values with the same letters within the same column were not significantly different $(P=$ 0.05 , Fisher's least significant difference).

${ }^{\mathrm{z}}$ Control efficacy $=[($ Lesion diameter of control - Lesion diameter of treated group $) /($ Lesion diameter of control -0.5$)] \times 100 \%$.

Table 1. Primers used in this study

\begin{tabular}{lll}
\hline Primer & \multicolumn{1}{c}{ Sequence $\left(\mathbf{5}^{\prime} \mathbf{-} \mathbf{3}^{\prime}\right)$} & \multicolumn{1}{c}{ Use $^{\mathbf{z}}$} \\
\hline P1 & CACCCAAAGCTTCCTCCATA & qRT-PCR primers for the Amrl gene \\
P2 & CAGGCGGAAGAAGAACAAAG & \\
P3 & GAGGACGAGATTGTCGGGTA & qRT-PCR primers for the $S c d 1$ gene \\
P4 & ACTCGAACCACCTGATGTCC & \\
P5 & GCGAGTACATTCCTGGTGGT & qRT-PCR primers for the Brn1 gene \\
P6 & GTTGACCCAGTCACCGTCTT & \\
P7 & GGACGTAACGGAGGAGATCA & qRT-PCR primers for the Brn2 gene \\
P8 & TCTTCGATGTGCTTGTACGC & \\
actin-F & GGCAACATTGTCATGTCTGG & qRT-PCR primers for analysis of actin gene expression \\
actin-R & GAGCGAAGCAAGAATGGAAC & \\
\hline
\end{tabular}

${ }^{\mathrm{z}}$ qRT-PCR, quantitative reverse-transcription PCR.

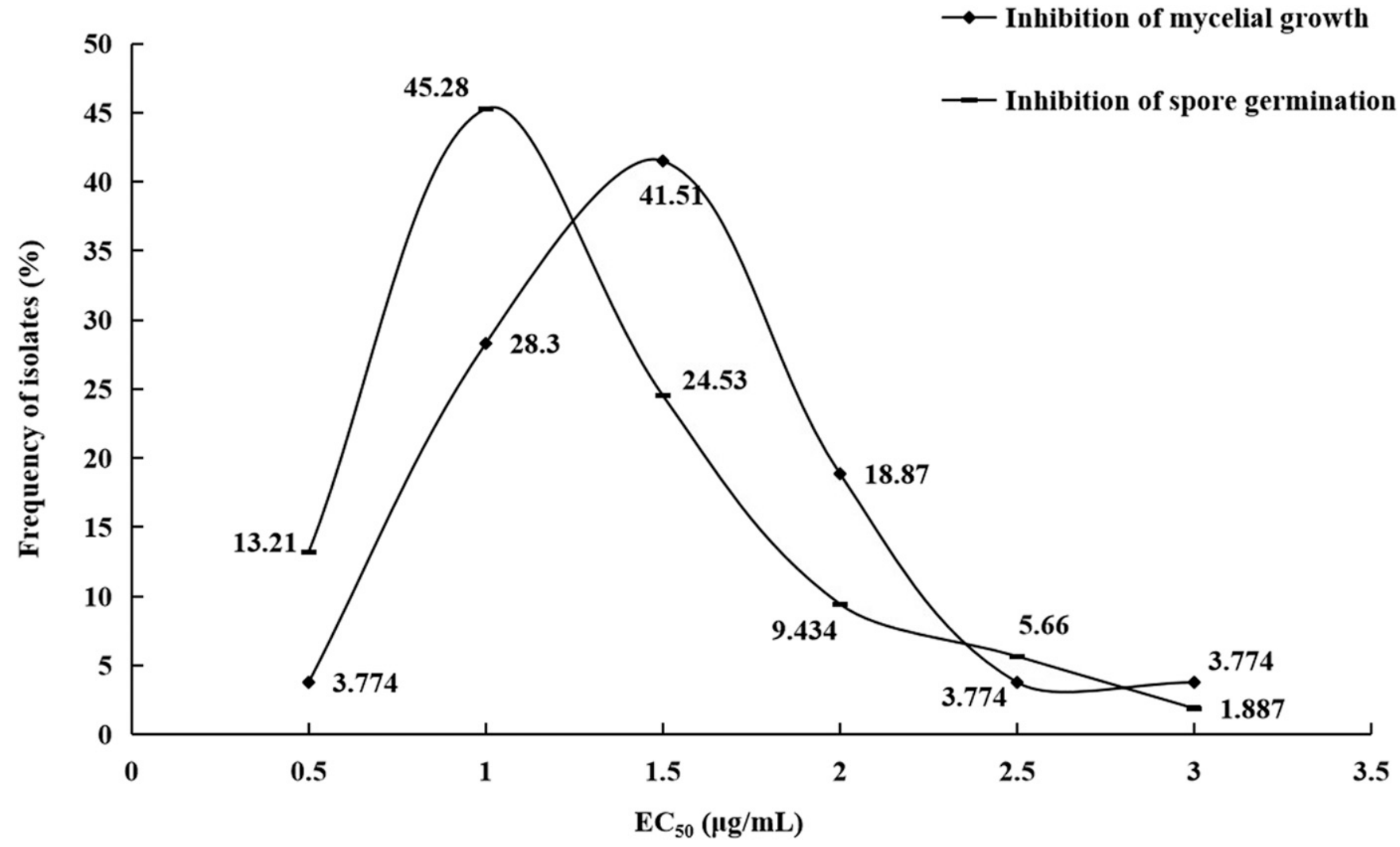

Fig. 1. Frequency distribution of propamidine $\mathrm{EC}_{50}$ values for 53 isolates of $A$. brassicicola by inhibiting mycelial growth and spore germination. 
$40 \%$ control efficacy was observed when treated with propamidine at $25 \mu \mathrm{g} / \mathrm{ml}$ (Table 2).

Effect of propamidine on mycelial and colony morphology. The SEM observations showed that the mycelia of A. brassicicola were severely distorted, with a brush-like cluster of hyphae at the hyphal tip on PDA supplemented with propamidine at their $\mathrm{EC}_{50}$ values (Fig. 2A; Supplementary Fig. S1). Observations using TEM showed that the mycelial cell wall of A. brassicicola was thicker than that of the untreated control (Fig. 2B; Supplementary Table S1). In addition, the colonies of both A. brassicicola isolates YL12 and RG5 were lighter in color when grown on PDA amended with propamidine at their respective $\mathrm{EC}_{10}$ or $\mathrm{EC}_{20}$ values than when grown on PDA with no amendments (Fig. 3).

Effect of propamidine on cell membrane permeability. The relative conductivity of the mycelia of A. brassicicola isolates YL12 and RG5 treated with or without propamidine increased over time.
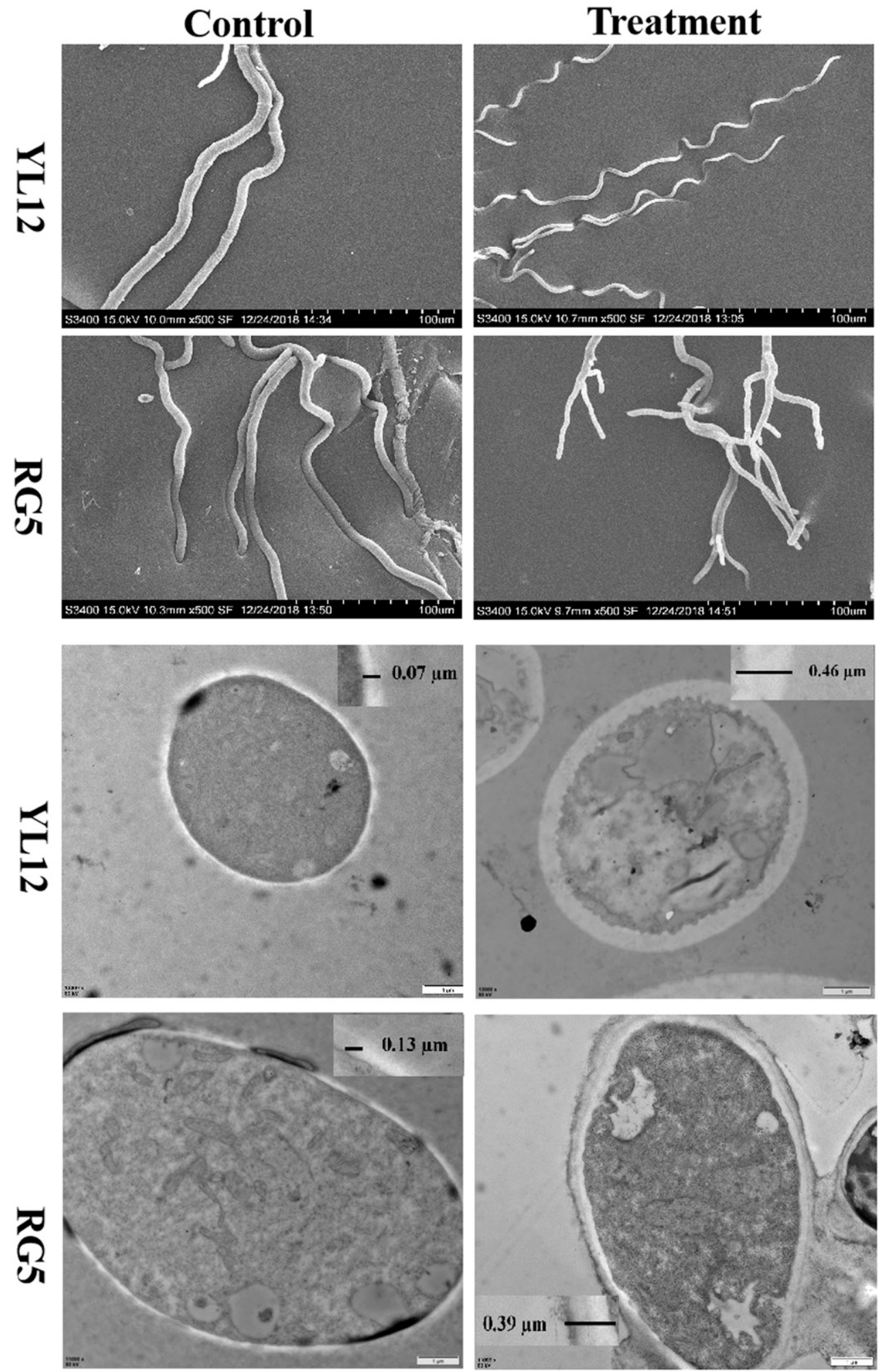

Fig. 2. Effect of propamidine on mycelial morphology of two wild-type A. brassicicola isolates (YL12 and RG5). Top four images: Scanning electron microscope (SEM) observations. Bottom four images: Transmission electron microscope (TEM) observations. 
Additionally, the relative conductivity of the mycelia treated with propamidine was always lower than that of the control (Fig. 4).

Effect of propamidine on chitin content. As shown in Figure 5, the natural chitin content of the mycelia of the two tested isolates differed from each other. When treated with propamidine at their $\mathrm{EC}_{50}$ values, however, the chitin content of A. brassicicola isolates YL12 and RG5 increased by 97 and 134\%, respectively.

Expression of melanin biosynthesis-associated genes. For both isolates examined, the expression levels of the Amrl, Scdl, Brnl, and $B r n 2$ genes involved in the melanin synthesis pathway differed from that of their respective controls. The expression levels of the four genes in YL12 and RG5 was downregulated after treatment with propamidine, especially the Amrl gene, which exhibited downregulated expression of $>60 \%$ (Fig. 6).

\section{Discussion}

Propamidine belongs to the chemical class of aromatic diamidine compounds. Currently, propamidine has been registered in China for the control of gray mold caused by $B$. cinerea on tomato and cucumber, but it has not been registered for the control of dark leaf spot on cabbage (Hou et al. 2010). In this study, propamidine sensitivity, as indicated by $\mathrm{EC}_{50}$ values, was determined for 53 isolates of $A$. brassicicola according to mycelial growth and spore germination inhibition. The average $\mathrm{EC}_{50}$ values of the 53 isolates for inhibiting mycelial growth and spore germination were $1.327 \mu \mathrm{g} / \mathrm{ml} \pm 0.198 \mu \mathrm{g} / \mathrm{ml}$ and $1.106 \pm 0.113 \mu \mathrm{g} /$ $\mathrm{ml}$, respectively. These values were lower than the average propamidine $\mathrm{EC}_{50}$ value $(1.616 \pm 0.217 \mu \mathrm{g} / \mathrm{ml})$ reported for $S$. sclerotiorum (Wang et al. 2017), and lower than that of azoxystrobin against $A$. brassicicola (mean $\mathrm{EC}_{50}$ value $2.49 \mu \mathrm{g} / \mathrm{ml}$ ) (Kreis et al. 2016). These low $\mathrm{EC}_{50}$ values and the narrow range of frequency distribution indicated that no resistant subpopulations were detected among the isolates used in this study. These sensitivity data could be used as a relative baseline for future monitoring of the shift of sensitivity in A. brassicicola populations to propamidine. Additional isolate collection from different locations and sensitivity tests are underway in our laboratory.

Pot experiments indicated that $>90 \%$ efficacy was observed when propamidine was applied at $100 \mu \mathrm{g} / \mathrm{ml}$, which was higher than the efficacy of the reference fungicide azoxystrobin at the same concentration. These results suggested that propamidine exhibits potential as an alternative candidate for the control of dark leaf spot on cabbage.

Chitin, a linear and insoluble homopolymer composed of $\beta-1,4$ linked subunits of the acetylated amino sugar $\mathrm{N}$-acetylglucosamine, is an essential structural component of the cell walls of filamentous fungi. It is the second most abundant polymer found in the biosphere (Seidl 2008). In this study, we observed that the mycelial cell wall of $A$. brassicicola isolates became thicker after treatment with propamidine, which was consistent with the results of treating $S$. sclerotiorum with propamidine (Wang et al. 2017). Moreover, the chitin content in $A$. brassicicola increased significantly after treatment with propamidine, which may be considered a protective measure from the damaging effects of the fungicide; this finding was consistent with the increased thickness of the mycelial cell wall of $A$. brassicicola. In addition, the mycelia were distorted, with more branches, and the relative conductivity was reduced after treatment with propamidine, indicating that propamidine could reduce the cell membrane permeability of A. brassicicola. This phenomenon was consistent with the results of treating S. sclerotiorum with prochloraz (Zhang et al. 2018).

Melanin, a dark brown or black pigment tissue produced by Alternaria species, is a ubiquitous pigment that has an important role in protecting fungi from the damaging effects of environmental stress; therefore, it may be considered an advantageous adaptation (Eliahu et al. 2007). Previous studies have demonstrated that melanin could enhance the tolerance of fungi to ultraviolet (UV) light, enzymatic lysis, and extreme temperatures (Rehnstrom and Free 1996; Rosas and Casadevall 1997; Wang and Casadevall 1994). In contrast, melanindeficient mutants were more sensitive to UV light, and the conidial
A
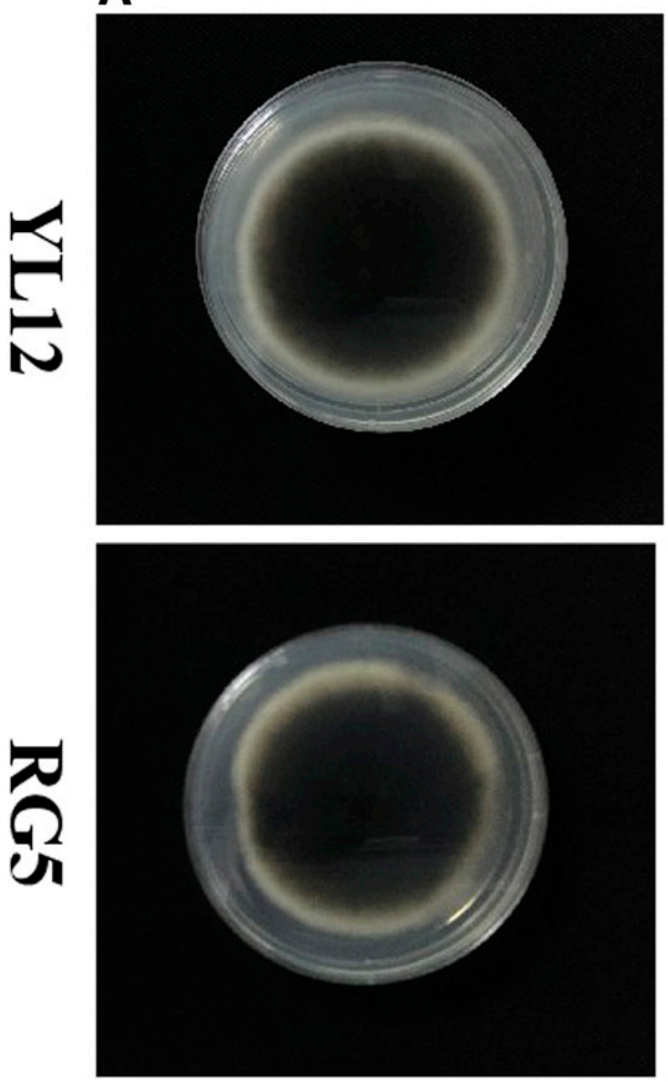

B
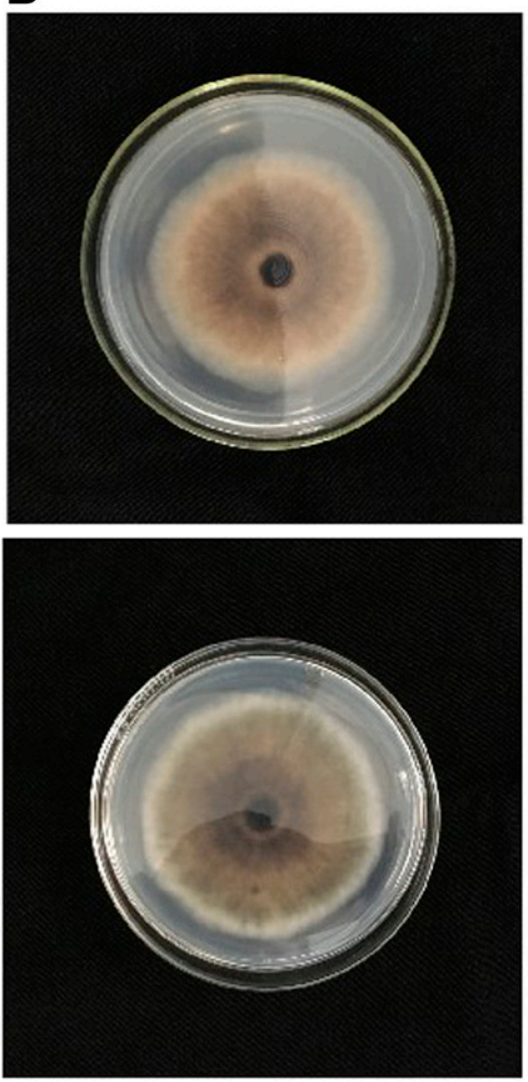

C
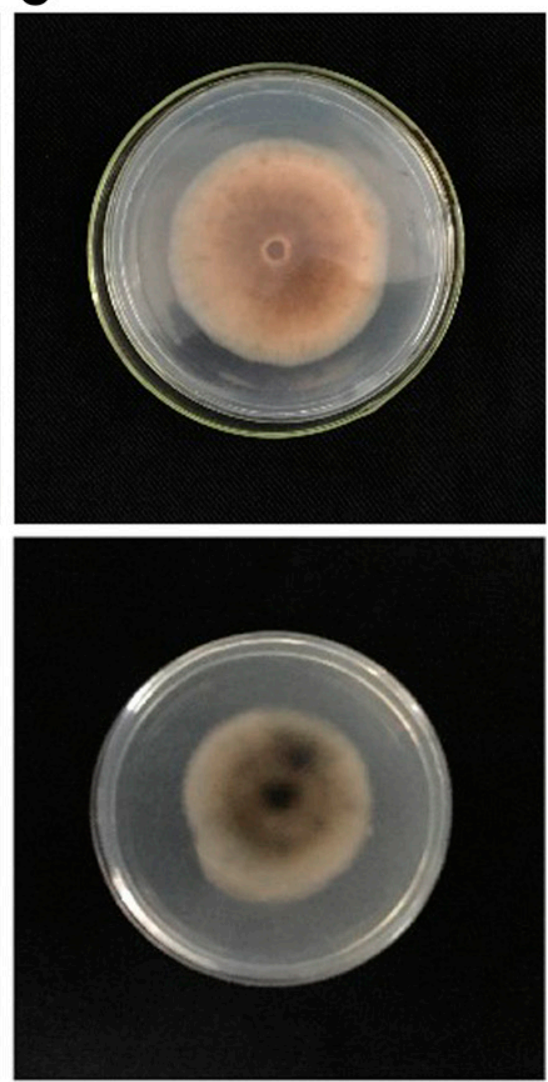

Fig. 3. Effect of different concentrations of propamidine ( $\mathrm{EC}_{10}$ and $\mathrm{EC}_{20}$ value) on colony morphology of two wild-type A. brassicicola isolates (YL12 and RG5). A, Untreated control. $B$, Propamidine at $\mathrm{EC}_{10}$ value. $\mathrm{C}$, Propamidine at $\mathrm{EC}_{20}$ value. 
size and septal number were reduced in A. alternata (Kawamura et al. 1999). Melanin is also required for the mechanical penetration of host plants by other phytopathogenic fungi, such as Magnaporthe grisea and Colletotrichum lagenarium (Kubo et al. 1991). Melanindeficient mutants of Cochliobolus heterostrophus lack pathogenicity under field conditions (Oide et al. 2006). Because of the lack of melanin standards, the melanin content was only qualitative in the present study. As shown in Figure 3, the black coloration of the $A$. brassicicola colonies decreased after treatment with propamidine, indicating a decrease in melanin content. In addition, studies have
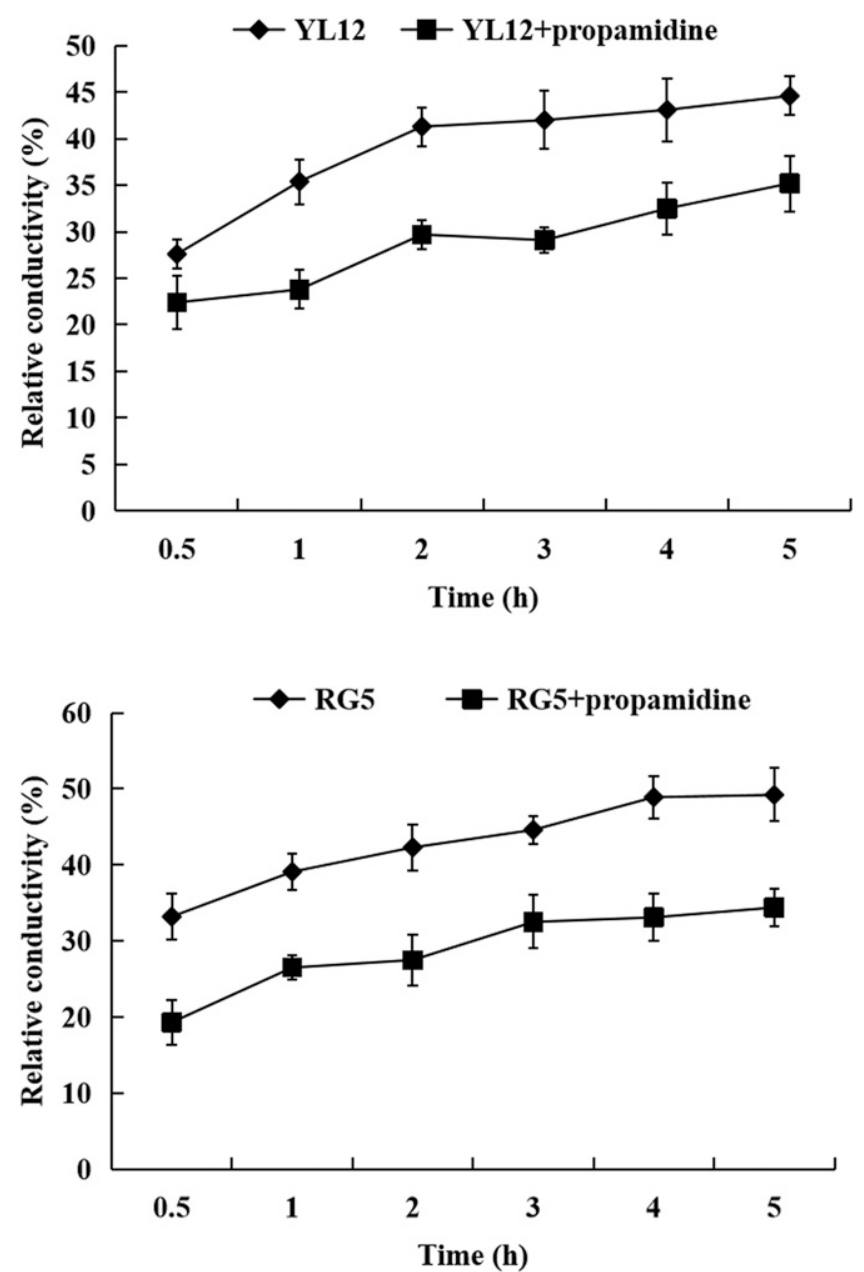

Fig. 4. Effect of propamidine on cell membrane permeability of mycelia of two wild-type A. brassicicola isolates (YL12 and RG5). Bars indicate the standard error of three experiments.

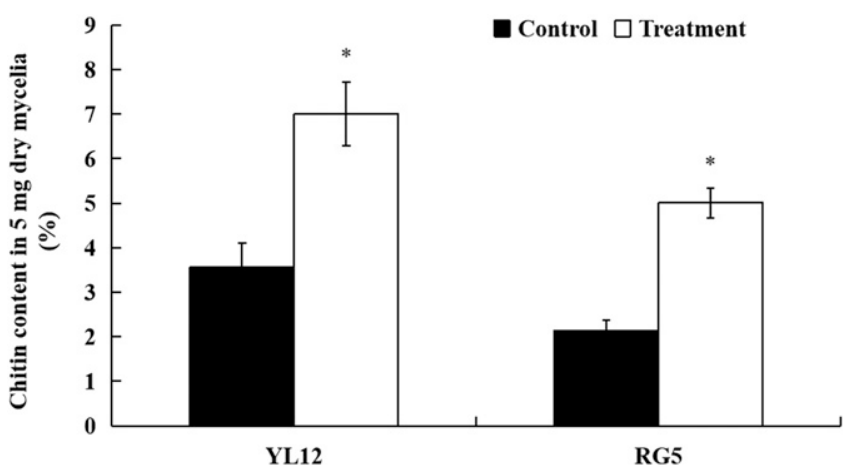

Fig. 5. Effect of propamidine on chitin content of two wild-type $A$. brassicicola isolates (YL12 and RG5). Asterisks indicate significant differences $(P<0.05)$ compared with the untreated control for each isolate.

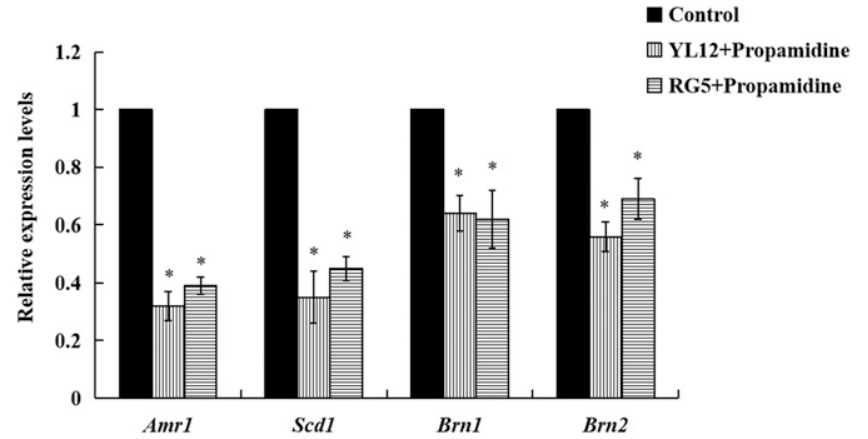

Fig. 6. Effect of propamidine on the expression of genes associated with melanin biosynthesis in $A$. brassicicola. Asterisks indicate significant differences $(P<0.05)$ compared with the untreated control for each gene.

shown that the Amr1, Scd1, Brn1, and Brn2 genes regulate melanin biosynthesis in A. brassicicola. The Amrl gene deletion mutant is melanin-deficient (Cho et al. 2012). Moreover, genes involved in melanin biosynthesis, including $S c d 1, B r n 1$, and $B r n 2$ genes, have been reported for Bipolaris oryzae, a rice pathogen closely related to $C$. heterostrophus, and for C. lagenarium (Kihara et al. 2004; Takano et al. 1997). Therefore, we quantified the expression levels of these four genes by qRT-PCR. After treatment with propamidine, the expression levels of these four genes were downregulated. These results indicated that propamidine inhibited melanin biosynthesis in our isolates of $A$. brassicicola, which may lead to the reduced tolerance of $A$. brassicicola to environmental stresses (such as UV radiation or extreme temperatures).

To our knowledge, this study is the first report the baseline sensitivity of A. brassicicola to propamidine and the significant potential value of this fungicide for controlling dark leaf spot on cabbage. Propamidine inhibited not only the mycelial growth of $A$. brassicicola but also melanin biosynthesis, which could reduce the biological fitness of A. brassicicola in field conditions. These results support the notion that propamidine may be a good alternative to commonly used fungicides for the management of dark leaf spot on cabbage. This information encourages further investigation of the mechanism of action of propamidine against other plant pathogens.

\section{Literature Cited}

Ayaz, F. A., Glew, R. H., Millson, M., Huang, H. S., Chuang, L. T., Sanz, C., and Hayirlioglu-Ayza, S. 2006. Nutrient contents of kale (Brassica oleraceae L. var. acephala DC.). Food Chem. 96:572-579.

Bartlett, D. W., Clough, J. M., Godwin, J. R., Hall, A. A., Hamer, M., and ParrDobrzanski, B. 2002. The strobilurin fungicides. Pest Manag. Sci. 58:649-662.

Beever, R. E., Laracy, E. P., and Park, H. A. 1989. Strain of Botrytis cinerea resistant to dicarboximide and benzimidazole fungicides in New Zealand vineyards. Plant Pathol. 38:427-437.

Chen, Y., Shang, H. H., Yang, H. Q., Gao, B. D., and Zhong, J. 2017. A mitovirus isolated from the phytopathogenic fungus Alternaria brassicicola. Arch. Virol. 162:2869-2874.

Chen, Y., and Zhou, M. G. 2009. Characterization of Fusarium graminearum isolates resistant to both carbendazim and a new fungicide JS399-19. Phytopathology 99:441-446.

Cho, Y., Srivastava, A., Ohm, R. A., Lawrence, C. B., Wang, K. H., Grigoriev, I. V., and Marahatta, S.P. 2012. Transcription factor Amrl induces melanin biosynthesis and suppresses virulence in Alternaria brassicicola. PLoS Pathog 8:e1002974.

Costa-de-Oliveira, S., Silva, A. P., Miranda, I. M., Salvador, A., Azevedo, M. M., Munro, C. A., Rodrigues, A. G., and Pina-Vaz, C. 2013. Determination of chitin content in fungal cell wall: An alternative flow cytometric method. Cytometry A 83A:324-328.

Eliahu, N., Igbaria, A., Rose, M. S., Horwitz, B. A., and Lev, S. 2007. Melanin biosynthesis in the maize pathogen Cochliobolus heterostrophus depends on two mitogen-activated protein kinases, Chk1 and Mps1, and the transcription factor Cmr1. Eukaryot. Cell 6:421-429.

Fortwendel, J. R., Juvvadi, P. R., Pinchai, N., Perfect, B. Z., Alspaugh, J. A., Perfect, J. R., and Steinbach, W. J. 2009. Differential effects of inhibiting chitin and 1,3- $\beta$-D-Glucan synthesis in ras and calcineurin mutants of Aspergillus fumigatus. Antimicrob Agents Ch. 53:476-482.

Gullino, M. L., Tinivella, F., Garibaldi, A., Kemmitt, G. M., Bacci, L., and Sheppard, B. 2010. Mancozeb: past present and future. Plant Dis. 94:1076-1087.

Hou, J., Gao, Y. N., Feng, J. T., Ma, Z. Q., and Zhang, X. 2010. Sensitivity of Botrytis cinerea to propamidine: in vitro determination of baseline sensitivity and the risk of resistance. Eur. J. Plant Pathol. 128:261-267. 
Iacomi-Vasilescu, B., Avenot, H., Bataille-Simoneau, N., Laurent, E., Guenard, M., and Simoneau, P. 2004. In vitro fungicide sensitivity of Alternaria species pathogenic to crucifers and identification of Alternaria brassicicola field isolates highly resistant to both dicarboximides and phenylpyrroles. Crop Prot. 23:481-488.

Kawamura, C., Tsujimoto, T., and Tsuge, T. 1999. Targeted disruption of a melanin biosynthesis gene affects conidial development and UV tolerance in the Japanese pear pathotype of Alternaria alternata. Mol. Plant-Microbe Interact. 12:59-63.

Kihara, J., Moriwaki, A., Ueno, M., Tokunaga, T., Arase, S., and Honda, Y. 2004. Cloning, functional analysis and expression of a scytalone dehydratase gene (SCD1) involved in melanin biosynthesis of the phytopathogenic fungus Bipolaris oryzae. Curr. Genet. 45:197-204.

Kim, K. H., Cho, Y., Rota, M. L., Cramer, J. R. R. A., and Lawrence, C. B. 2007. Functional analysis of the Alternaria brassicicola non-ribosomal peptide synthetase gene AbNPS2 reveals a role in conidial cell wall construction. Mol. Plant Pathol. 8:23-39.

Köller, W. 2002. Resistance to strobilurin fungicides. Acs Symposium. 808:215-229.

Kreis, R. A., Dillard, H. R., and Smart, C. D. 2016. Population diversity and sensitivity to azoxystrobin of Alternaria brassicicola in New York State. Plant Dis. 100:2422-2426.

Kubo, Y., Nakamura, H., Kobayashi, K., Okuno, T., and Furusawa, I. 1991. Cloning of a melanin biosynthetic gene essential for appressorial penetration of Colletotrichum lagenarium. Mol. Plant-Microbe Interact. 4:440-445.

Livak, K. J., and Schmittgen, T. D. 2001. Analysis of relative gene expression data using real-time quantitative PCR and the $2^{-\Delta \Delta \mathrm{Ct}}$ method. Methods 25:402-408.

Ma, H. X., Feng, X. J., Chen, Y., Chen, C. J., and Zhou, M. G. 2009. Occurrence and characterization of dimethachlon insensitivity in Sclerotinia sclerotiorum in Jiangsu Province of China. Plant Dis. 93:36-42.

Malandrakis, A. A., Apostolidou, Z. A., Markoglou, A., and Flouri, F. 2015. Fitness and cross-resistance of Alternaria alternata field isolates with specific or multiple resistance to single site inhibitors and mancozeb. Eur. J. Plant Pathol. 142:489-499.

Manhas, R. K., and Kaur, T. 2016. Biocontrol potential of Streptomyces hydrogenans strain DH16 toward Alternaria brassicicola to control damping off and black leaf spot of Raphanus sativus. Front. Plant Sci. 7:1869.

Mc, A. H. 2010. Some variants and possible errors in the test-tube dilution and slide-germination methods for laboratory testing of fungicides. Ann. Appl. Biol. 49:424-432.

Nowakowska, M., Wrzesinska, M., Kaminski, P., Szczechura, W., Lichocka, M., Tartanus, M. U., Kozik, E., and Nowicki, M. 2019. Alternaria brassicicola Brassicaceae pathosystem: insights into the infection process and resistance mechanisms under optimized artificial bio-assay. Eur. J. Plant Pathol. 153:131-151.

Oide, S., Moeder, W., Krasnoff, S., Gibson, D., Haas, H., Yoshioka, K., and Turgeon, B. G. 2006. NPS6, encoding a nonribosomal peptide synthetase involved in siderophore-mediated iron metabolism, is a conserved virulene determinant of plant pathogenic Ascomycetes. Plant Cell 18:2836-2853.

Pedras, M. S. C., Chumala, P. B., Jin, W., Islam, M. S., and Hauck, D. W. 2009. The phytopathogenic fungus Alternaria brassicicola: Phytotoxin production and phytoalexin elicitation. Phytochemistry 70:394-402.

Rehnstrom, A. L., and Free, S. J. 1996. The isolation and characterization of melanin-deficient mutants of Monilinia fructicola. Physiol. Mol. Plant Pathol. 49:321-330.
Rosas, A. L., and Casadevall, A. 1997. Melanization affects susceptibility of Cryptococcus neoformans to heat and cold. FEMS Microbiol. Lett. 153: 265-272.

Seidl, V. 2008. Chitinases of filamentous fungi: a large group of diverse proteins with multiple physiological functions. Fungal Biol. Rev. 22:36-42.

Srivastava, A., Ohm, R. A., Oxiles, L., Brooks, F., Lawrence, C. B., Grigoriev, I. V., and Cho, Y. 2012. A Zinc-finger-family transcription factor, AbVf19, is required for the induction of a gene subset important for virulence in Alternaria brassicicola. Mol. Plant-Microbe Interact. 25:443-452.

Takano, Y., Kubo, Y., Kuroda, I., and Furusawa, I. 1997. Temporal transcriptional pattern of three melanin biosynthesis genes, PKS1, SCD1, and THR1, in appressorium-differentiating and nondifferentiating conidia of Colletotrichum lagenarium. Appl. Environ. Microbiol. 63:351-354.

Tsuji, G., Kenmochi, Y., Takano, Y., Sweigard, J., Farrall, L., Furusawa, I. Horino, O., and Kubo, Y. 2002. Novel fungal transcriptional activators, Cmrlp of Colletotrichum lagenarium and Piglp of Magnaporthe grisea, contain Cys2His2 zinc finger and Zn(II)2Cys6 binuclear cluster DNAbinding motifs and regulate transcription of melanin biosynthesis genes in a developmentally specific manner. Mol. Microbiol. 38:940-954

Walker, L. A., Munro, C. A., Brujin, I. D., Lenardon, M. D., McKinnon, A., and Gow, N. A. R. 2008. Stimulation of chitin synthesis rescues Candida albicans from echinocandins. PLoS Pathog 4:e1000040.

Wang, M. Q., Zhao, X. J., Liu, H. P., and Han, J. C. 2005. Resistance detection of Fulvia fulva to mancozeb. J Shanxi Agricul Sci. 33:66-68.

Wang, Y., and Casadevall, A. 1994. Decreased susceptibility of melanized Cryptococcus neoformans to UV light. Appl. Environ. Microbiol. 60:3864-3866.

Wang, Y., Sun, Y., Xiong, Z., He, K., Feng, J. T., and Zhang, X. 2018. Baseline sensitivity and biochemical responses of Valsa mali to propamidine. Pestic. Biochem. Physiol. 147:90-95.

Wang, Y., Sun, Y., Zhang, Y., Zhang, Y. X., Han, L. R., Zhang, X., and Feng, J. T. 2017. Sensitivity and biochemical characteristics of Sclerotinia sclerotiorum to propamidine. Pestic. Biochem. Physiol. 135:82-88.

Xu, C. Y., Liang, X. Y., Hou, Y. P., and Zhou, M. G. 2015. Effects of the novel fungicide benzothiostrobin on Sclerotinia sclerotiorum in the laboratory and on Sclerotinia stem rot in rape fields. Plant Dis. 99:969-975.

Yang, M., Feng, S. J., He, Y. Y., Wang, Z., and Zhou, E. X. 2013. Screening of efficient fungicides for the control of citrus anthracnose and the discovery of fungicide-resistant isolates. J South China Agricul Univ. 34:28-31.

Zhang, H. F., Liu, K. Y., Zhang, X., Song, W. W., Zhao, Q., Dong, Y. H., Guo, M. Zheng, X. B., and Zhang, Z. G. 2010. A two-component histidine kinase, MoSLN1, is required for cell wall integrity and pathogenicity of the rice blast fungus, Magnaporthe oryzae. Curr. Genet. 56:517-528.

Zhang, R., Xu, Q. R., Zhang, Y. C., and Zhu, F. X. 2018. Baseline sensitivity and toxic actions of prochloraz to Sclerotinia sclerotiorum. Plant Dis. 102 2149-2157

Zhang, X. K., Wu, D. X., Duan, Y. B., Ge, C. Y., Wang, J. X., Zhou, M. G., and Chen, C. J. 2014. Biological characteristics and resistance analysis of the novel fungicide SYP-1620 against Botrytis cinerea. Pestic. Biochem. Physiol. 114 $72-78$

Zhang, Z. Y., Liu, X. J., Yu, X. Y., Zhang, C. Z., and Hong, X. Y. 2007. Pesticide residues in the spring cabbage (Brassica oleracea L. var. capitata) grown in open field. Food Control 18:723-730. 